\title{
Deleterious point mutations in T-cell acute lymphoblastic leukemia: Mechanistic insights into leukemogenesis
}

\author{
Urbi Roy | Sathees C. Raghavan (1)
}

Department of Biochemistry, Indian Institute of Science, Bangalore, India

\section{Correspondence}

Sathees C. Raghavan, Department of Biochemistry, Indian Institute of Science, Bangalore 560012, India.

Email: sathees@iisc.ac.in

Funding information

DBT-COE, Grant/Award Number: BT/ PR13458/COE/34/33/2015; DBT-IISc, Grant/ Award Number: BT/

PR27952-INF/22/212/2018; Glue-Grant, Grant/Award Number: BT/PR23078/ MED/29/1253/2017; Senior Research Fellowship (SRF) from IISc

\begin{abstract}
T-cell acute lymphoblastic leukemia (T-ALL) is characterized by the leukemogenic transformation of immature $T$ cells, which accumulate an array of genetic and epigenetic lesions, leading to a sustained proliferation of abnormal T cells. Genetic alterations in the DNA repair genes, protooncogenes, transcription factors, and epigenetic modifiers have been studied in the past decade using next-generation sequencing and high-resolution copy number arrays. While other genomic lesions like chromosomal rearrangements, inversions, insertions, and gene fusions have been well studied at functional level, the mechanism of generation of driver mutations in T-ALL is the subject of current investigation. Novel oncogenic mutations in the TP53, BRCA2, PTEN, IL7R, RAS, NOTCH1, ETV6, BCL11B, WT1, DNMT3A, PRC2, PHF6, USP7, KDM6A and an array of other genes disrupt the genetic and epigenetic homeostasis in T-ALL. In this review, we have summarized the mechanistic role of deleterious driver mutations in T-ALL initiation and progression. We speculate that the formation of non-B DNA structures could be one of the primary reasons for the occurrence of different genomic lesions seen in T-ALL, which warrants further investigation. Understanding the mechanism behind the genesis of oncogenic mutations will pave the way to develop targeted therapies that can improve the overall survival and treatment outcome.
\end{abstract}

\section{KEYWORDS}

chromosomal rearrangements, driver mutations, genomic instability, lymphoid cancer, non-B DNA structures
Abbreviations: AID, activation-induced cytidine deaminase; ALL, acute lymphoblastic leukemia; AML, acute myeloid leukemia; CALL, childhood acute lymphoblastic leukemia; CLL, chronic lymphocytic leukemia; CML, chronic myeloid leukemia; D2HG, D-2-hydroxyglutarate; DN, double-negative; DP, double-positive; ETP-ALL, early T-cell precursor ALL; EZH2, enhancer of zeste homolog 2; GSIs, $\gamma$-secretase inhibitors; HATs, histone acetyltransferase; $\mathrm{HD}$, heterodimerization domain; HDACs, histone deacetylases; HSC, hematopoietic stem cell; IDH, isocitrate dehydrogenases; NLS, nuclear localization signals; PATRR, palindromic AT rich repeat; PHD, plant homeodomain; PHF6, plant homeodomain finger 6; PIP2, phosphatidylinositol (4, 5); SP, single-positive; SUZ12, suppressor of zeste 12 homolog; TALL, T-cell acute lymphoblastic leukemia; TSP, thymic seeding progenitors; USP7, ubiquitinspecific-processing protease 7; UTX, ubiquitously transcribed X.

\section{1 | INTRODUCTION}

Among different cancers, treatment of leukemia remains a challenge due to its invasiveness, poor response to therapy, and frequent relapses. Globally, it is estimated that around 300000 new cases of leukemia are detected annually, which accounts for $2.8 \%$ of all new cancer cases. ${ }^{1,2}$ The 5 -year event-free survival rate for ALL is $80 \%$ or more in children and younger adults. ${ }^{3}$ According to WHO, the common subtypes of leukemia are acute myeloid leukemia (AML), chronic myeloid leukemia (CML), acute lymphoblastic leukemia ( $A L L)$, and chronic lymphocytic leukemia (CLL). ALL and CLL can be further subdivided into B-ALL/B-CLL and T-ALL/T-CLL depending on whether it 
has originated from B-lymphocytes or T-lymphocytes ${ }^{4}$ (Figure S1) Pathogenesis of T-ALL involves abnormal proliferation and differentiation of a clonal population of immature thymocytes. Clinical symptoms of T-ALL include an increase in the number of white blood cells, bulky adenopathy, and disorders of the central nervous system.

The abnormal division of $\mathrm{T}$ cells is a direct consequence of the accumulation of a plethora of genetic abnormalities like chromosomal rearrangements $\mathrm{t}(5 ; 14)(\mathrm{q} 35 ; \mathrm{q} 11), \mathrm{t}(11 ; 14)(\mathrm{p} 13 ; \mathrm{q} 11)$, activating mutations, loss-of-function mutations, gene fusions, inversions, deletions, gene duplications, and epigenetic mutations. ${ }^{5,6}$ While genetic aberrations like translocations, large-scale deletions, and gene fusions in leukemia have been explored widely, the mechanism behind the generation of point mutations in protooncogenes, tumor suppressor genes, DNA repair genes, epigenetic regulatory enzymes, and so forth is being investigated in leukemia. For example, the tumor suppressor gene TP53 is mutated in $15.7 \%$ of ALL cases with a higher mutation load in B-ALL compared to T-ALL, ${ }^{7}$ while the signaling protein NOTCH1 is mutated in $53 \%$ of T-ALL patients. ${ }^{8}$ Similarly, several genes belonging to the category of epigenetic regulators, DNA repair, transcription factors are mutated at varying frequencies in T-ALL (Table 1). The aberrant expression of these mutated genes is associated with the relapse of T-ALL, poor prognosis, and increased antineoplastic resistance. ${ }^{7,9-11}$ This review highlights the mechanistic role and implications of mutated genes in T-cell acute lymphoblastic leukemia. We also summarize how the dysregulation of such critical genes of the cell enhance the proliferative capacity of immature T lymphocytes, leading to the pathogenesis of T-ALL.

\section{2 | T-CELL DEVELOPMENTAL PROGRAM IN MICE AND HUMAN}

T-cell development in thymus provides the favorable microenvironment for its maturation, differentiation, and lineage specification. ${ }^{12}$ Natural competition between bone marrow-derived progenitors and intrathymic progenitors maintain the turnover of T lymphocytes in the thymus. ${ }^{13}$ The persistence of intrathymic bone marrow precursors capable of self-renewing activates aberrant genetic programs, culminating into T-ALL. ${ }^{13}$

TAB LE 1 Mutation frequency of a panel of driver genes in pediatric vs adult T-ALL

\begin{tabular}{|c|c|c|c|c|c|}
\hline \multirow[b]{2}{*}{ Gene } & \multirow[b]{2}{*}{ Types of mutation } & \multicolumn{2}{|c|}{ Mutation freq. (\%) } & \multirow[b]{2}{*}{ Major consequence of the mutation } & \multirow[b]{2}{*}{ Reference } \\
\hline & & pT-ALL & Adult T-ALL & & \\
\hline TP53 & $\begin{array}{l}\text { Missense, frameshift, in-frame, splice site and } \\
\text { nonsense mutations }\end{array}$ & 23 & 15.7 & Gain of oncogenic activity & 7 \\
\hline BRCA2 & Missense, nonsense, splice site & 10 & - & $\begin{array}{l}\text { Loss of tumor-suppressor function, Fanconi } \\
\text { anemia }\end{array}$ & 35 \\
\hline$B C L 11 B$ & Missense, frameshift deletion and insertion & 8 & 14 & $\begin{array}{l}\text { T cells acquire an NK-cell like property and stop } \\
\text { differentiating }\end{array}$ & 11,56 \\
\hline ETV6 & $\begin{array}{l}\text { Frameshift insertion, missense, nonsense, splice } \\
\text { site }\end{array}$ & 5 & 14 & Loss of transcription repression activity & 63,80 \\
\hline GATA3 & Missense, in-frame deletion, splice site insertion & 8 & 3 & Loss of its transcriptional activity & 80 \\
\hline RUNX1 & Frameshift, splice site, missense & - & 10 & $\begin{array}{l}\text { Loss of transcription repression activity; } \\
\text { juxtaposition with ETV6 }\end{array}$ & 80 \\
\hline DNMT3A & Frameshift, missense, nonsense, splice site & $6-14$ & $4-18$ & $\begin{array}{l}\text { Mutation in catalytic domain decreases its } \\
\text { methyltransferase activity }\end{array}$ & $52,67,69$ \\
\hline TET1 & Missense & - & $6-14$ & $\begin{array}{l}\text { Aberrant distribution of histone modification } \\
\text { marks }\end{array}$ & 74 \\
\hline IDH1 & Missense & - & $2-6$ & Expression of myeloid genes in T-cells & $10,74,77$ \\
\hline IDH2 & Missense & $11-18$ & $5-9$ & Expression of myeloid genes in T-cells & $10,74,77$ \\
\hline$E Z H 2$ & Missense, frameshift insertion & $6-11$ & $11-18$ & Loss of PRC2 tumor suppressor activity & 74,80 \\
\hline SUZ12 & Frameshift deletion & $5-10$ & $6-11$ & Loss of PRC2 tumor suppressor activity & 74,80 \\
\hline EED & Missense, frameshift insertion & 2 & $5-10$ & Loss of PRC2 tumor suppressor activity & 74,80 \\
\hline EP300 & In-frame insertion, missense, splice site & 19 & 2 & Loss of histone acetyltransferase activity & 74 \\
\hline PHF6 & $\begin{array}{l}\text { Frameshift, in-frame mutation, missense, } \\
\text { nonsense, splice site }\end{array}$ & 8 & $30-38$ & $\begin{array}{l}\text { Aberrant expression of T-cell transcription } \\
\text { factor, } T L X 1 \text { and } T L X 3\end{array}$ & 93 \\
\hline USP7 & Frameshift, missense & $1-4$ & Rare & Loss of deubiquitinase activity & 64 \\
\hline HDAC5/7 & - & - & $1-4$ & Loss of histone deacetylase activity & 74 \\
\hline KDM6A & Frameshift, missense & - & 4.5 & Loss of histone demethylase activity & 85 \\
\hline
\end{tabular}

Note: A cohort of genes harboring mutations in pediatric vs adult T-ALL and its role in the progression of T-ALL. The different mutation frequencies reported here are based on several previously published studies that analyzed pediatric and adult T-ALL patient cohorts. "pT-ALL" indicates pediatric T-ALL. 
In the thymus, the progenitors fully commit to T-cell lineage by activating T-cell specific transcriptional program. ${ }^{14}$ In both humans and mice, differentiation of progenitors into double-negative (DN) thymocytes commits them to the T-cell lineage. The productively rearranged $\mathrm{TCR} \alpha \beta$ complexes at this stage provide the necessary signal to progress into the $\mathrm{CD}^{+} \mathrm{CD} 4^{+} \mathrm{CD} 8^{+}$(DP), double-positive stage. ${ }^{15}$ The second phase of selection involves three key components consisting of negative selection to eliminate strong self-reactive clones, positive selection of $\mathrm{T}$ cells that can recognize self-antigens bound to self-MHC molecules, and death by neglect. ${ }^{16}$ The positive selection gives rise to $\mathrm{CD} 4^{+} \mathrm{CD} 8-\mathrm{CD}^{+}$or $\mathrm{CD} 8^{+} \mathrm{CD} 4-\mathrm{CD} 3^{+}$(SP) single-positive cells that ultimately emerge as peripheral naïve $T$ cells (Figure S2). ${ }^{17} \mathrm{~A}$ fraction of peripheral $\mathrm{T}$ cells enter into a memory phase, in which long-term memory $T$ cells protect against subsequent infection. ${ }^{18}$ An array of transcription factors regulates the maturation, differentiation, and lineage specification of $T$ cells. Notch signaling sets up the platform for induction of T-cell specific genes, TCF7, GATA3, and BCL11B, which orchestrates the T-cell program and seals off the T-cell commitment fate. ${ }^{19,20}$

\section{3 | GENETIC PROFILE OF T-ALL}

During the onset or progression of the T-cell developmental program, preleukemic clones accumulate a number of genetic alterations, which cooperate to disrupt the genetic equilibrium of the cell. T-ALL is one such cancer where a deleterious mutation remarkably changes the cancer genetics, requiring the development of targeted therapies against the specific mutations. The driver genes which majorly contribute to the mutational spectrum in T-ALL are listed below.

\subsection{DNA repair genes}

\section{\begin{tabular}{l|l}
3.1 .1 & TP53
\end{tabular}}

The tumor suppressor TP53 undergoes a large number of genetic changes, among which gain-of-function mutations majorly contribute to its inactivation in hematopoietic and nonhematopoietic malignancies. $^{21}$ Interestingly, greater than $60 \%$ of human T-cell leukemia cell lines derived from relapse T-ALL cases showed activating mutation in both the p53 alleles. $^{7,22,23}$ The mutations and deletions of the $p 53$ gene in the initial diagnosis phase of both childhood and adult T-ALL were rarely observed, bringing into question the exact mechanism of p53-driven T-ALL. ${ }^{23,24}$ An in-depth analysis of T-ALL patient samples from both diagnosis and relapse phase clearly shows that around $20 \%$ to $30 \%$ of relapse cases possess mutations in the $p 53$ gene. $^{23,25-27}$ This was associated with a poor treatment outcome, reduced duration of survival after the first remission, diminished response to reinduction therapy, and increased fatality. ${ }^{7,23,26,28}$ On a functional level, mutant p53 helps cancer cells maintain high glycolytic output, protects against oxidative stress, blocks apoptosis, promotes metastasis, and increases antineoplastic resistance. ${ }^{29}$ p53 - /- mice spontaneously develop T and B cell lymphomas, owing to a loss of tumor-suppressive activity. ${ }^{30}$ p53 loss is required for both tumor initiation and maintenance, making it a promising therapeutic strategy in cancer patients. ${ }^{31}$ A study by Hsiao et al showed that transplantation of only the T-ALL cell line (CEM) harboring independent mutations of both $\mathrm{p} 53$ alleles was capable of causing tumor cell proliferation and hematological disorder in SCID mice ${ }^{32}$ whereas the presence of either wild-type $\mathrm{p} 53$ or no $\mathrm{p} 53$ protein did not lead to such a phenotype. Further, infection of p53-negative Be-13T-ALL cells with viruses encoding dominant and activating mutant $\mathrm{p} 53$ genes resulted in the acquisition of metastatic potential and tissue invasiveness. $^{32}$

Therefore, mutational activation of $p 53$ causes a genetic imbalance, especially in relapsed T-ALL cases, leading to the clonal selection of tumorigenic T cells.

\subsection{2 | BRCA2}

The Fanconi Anemia (FA) pathway maintains genomic integrity and stability by repairing DNA interstrand crosslinks and stalled replication forks. ${ }^{33}$ Consequently, patients with Fanconi anemia develop congenital abnormalities along with an increased predisposition to leukemia. ${ }^{34}$ BRCA2, identical to FANCD1, is a vital component of the Fanconi pathway, which suppresses the transformation of immature $\mathrm{T}$ cells in mice. ${ }^{35}$ Mice harboring mutation in Brca2 undergo extensive chromosomal breakage, rearrangements promoting the development of T-cell lymphomas. $^{36,37}$ Murine cells with truncated Brca2 accumulate DNA breaks, replicative failure, elevated p53 and p21 expression, and aberrant chromatid exchanges, reinforcing the role of BRCA2 in DNA repair. ${ }^{38,39}$ BRCA2, a component of the Fanconi-BRCA DNA repair pathway harbors a monoallelic mutation in $23 \%$ of childhood T-ALL cases, conferring an incomplete Fanconi-BRCA pathway inactivation. ${ }^{35}$ Thus, a partially active Fanconi pathway may be required for the $T$ cells to fully transform into leukemic cells in cooperation with other oncogenic events. ${ }^{35}$ Interestingly, the BRCA2 haploinsufficient cells were prone to DNA damage and exhibited increased sensitivity to UV radiation. ${ }^{35}$ An independent study by Hirsch et al led to the association of biallelic BRCA2/ FANCD1 mutations with an increased predisposition to solid tumors and early onset of T-ALL in the D1 subtype of FA. ${ }^{40} \mathrm{How}$ ever, further investigation is required to establish the exact role of $B R C A 2$ in T-ALL disease progression.

\section{2 | Signaling pathways}

Genomic alterations in the genes associated with the cell survival and proliferating pathways, namely, RAS, PI3-AKT, and NOTCH, have been recently discussed in numerous reviews. ${ }^{6,41-43}$ Here, we summarize the impact of the somatic point mutations in altering the genomic landscape in T-ALL. 


\subsection{1 | IL-7-IL-7R}

The IL-7-IL-7R signaling pathway required for the normal development and maintenance of the immune system, harbors mutations in $9 \%$ of pediatric T-ALL and $12 \%$ of adult T-ALL cases (Figure S3A). ${ }^{2,44}$ Mice with IL-7 or IL-7R deficiency showed impaired thymocyte development and reduced numbers of peripheral T cells. ${ }^{45}$ In association with mutated PTEN, these genetic aberrations impart a survival advantage to the tumor cells by upregulating $\mathrm{PI} 3 \mathrm{~K} / \mathrm{Akt} / \mathrm{mTOR}$ pathway. In addition, oncogenic mutations of the downstream signaling genes, for example, JAK/STAT and $\mathrm{PI} 3 \mathrm{~K} / \mathrm{AKT} / \mathrm{mTOR},(\sim 10 \%-30 \%)^{2,46,47}$ make this pathway an ideal candidate for the development of targeted therapies in T-cell leukemia (Figure S3B).

\subsection{2 $\quad$ NOTCH1 signaling}

The NOTCH1 protein, required during different stages of T-cell development, can undergo $t(7 ; 9)$ translocations leading to human T-ALLs (Figure 1A). ${ }^{8,48}$ The NOTCH1 heterodimerization domain (HD) mutants mainly result in in-frame deletions and insertions conferring ligandhypersensitivity or ligand-independent NOTCH1 activation in T-ALL (Figure 1B). ${ }^{49}$ The NOTCH1 $\triangle P E S T$ mutations lead to upregulation of activated $\mathrm{NOTCH} 1$ due to impaired degradation of the activated receptor by the proteasome complex (Figure $1 \mathrm{C}$ ), ${ }^{50}$ which, in turn, promotes cell growth, proliferation, premature entry into the S-phase, and a host of other mutagenic events. ${ }^{51}$

\section{3 $\quad$ Transcription factors}

Deregulation of transcription factors by activating/loss-of-function mutations is a common mechanism by which T-cell progenitors gain oncogenic properties to progress into a malignant state. T-ALL is classified into three different subgroups; thymic-T-ALL, pediatric T-ALL, and adult T-ALL, based on the ectopic expression of one particular transcription factor (TAL1, TLX1, TLX3, LMO2) and other distinct genes, ${ }^{52}$ some of which are described below.

\subsection{1 $\quad$ BCL11B}

The transcription factor known to play a key role in maintaining the identity and differentiation of $\mathrm{T}$ cells is BCL11B, which is highly expressed at the DN stages of T-cell development. ${ }^{53,54}$ It acts as a tumor suppressor gene in mice, while in humans, it displays a contextdependent protooncogenic or tumor-suppressive function. ${ }^{54}$

Several studies suggest that missense mutations or deletions in BCL11B ( 15\%), in human T-ALL cases, confer NK-cell like properties to $T$ cells, resulting in sustained proliferation and survival of immature T cells. ${ }^{55,56}$ The mutation load is significantly higher ( 14\%) in Exon 4 of $B C L 11 B$ compared to the other three exons (Figure $2 A){ }^{11}$ These mutations disrupt the structure of the zinc finger domains and abrogate the transcription factor binding to DNA. ${ }^{11}$ In addition, BCL11B has also been implicated in the development of T-cell lymphomas/ leukemia by its frequent involvement in various translocations, for example, $\mathrm{t}(5 ; 14)(\mathrm{q} 35 ; 32){ }^{57}$
(A)

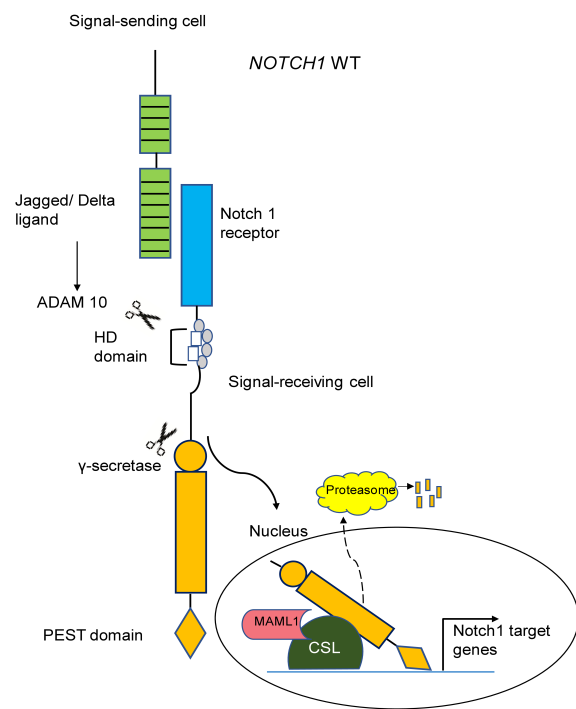

(B)

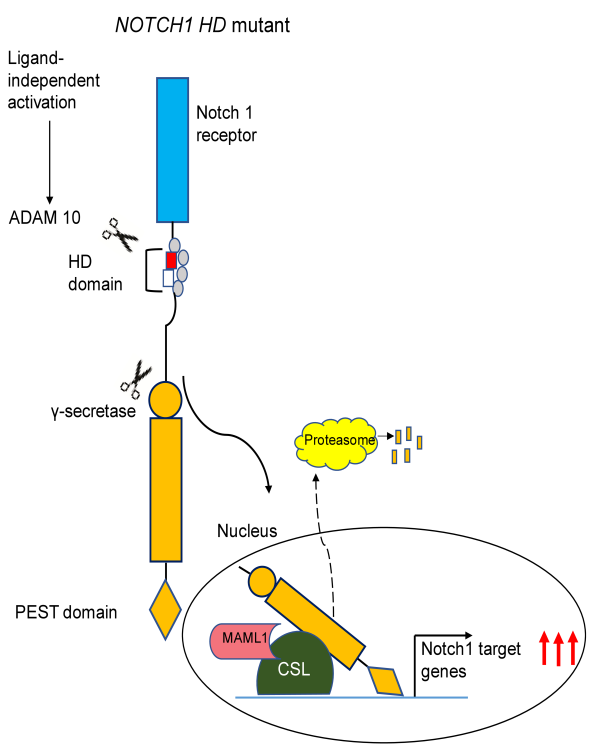

(C)

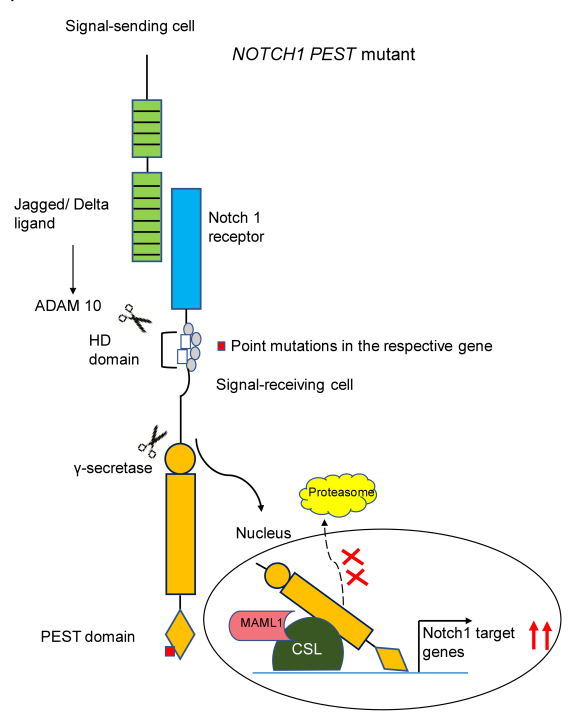

FIGURE 1 Aberrant NOTCH 1 signaling in T-ALL. A, Binding of the Notch 1 receptor to Jagged/Delta ligand triggers the proteolytic cleavage of the receptor, first by an ADAM metalloprotease followed by the $\gamma$-secretase complex, which releases the intracellular domains of NOTCH1 from the membrane. In the nucleus, this domain interacts with DNA via the CSL DNA binding protein and recruits the MAML1 coactivator to activate the expression of NOTCH1 target genes. Once the target genes are activated, the NOTCH1 receptor is degraded in the cytoplasm by the proteasome complex. B, Mutation in the HD domain leads to ligand-independent activation of NOTCH1 and overexpression of NOTCH1 target genes, enhancing cell survival and proliferation. C, Mutation in the NOTCH1 PEST domain leads to constitutive activation of NOTCH1 signaling by preventing the degradation of the receptor by the proteasome complex. Red squares indicate point mutations [Color figure can be viewed at wileyonlinelibrary.com] 
(A)

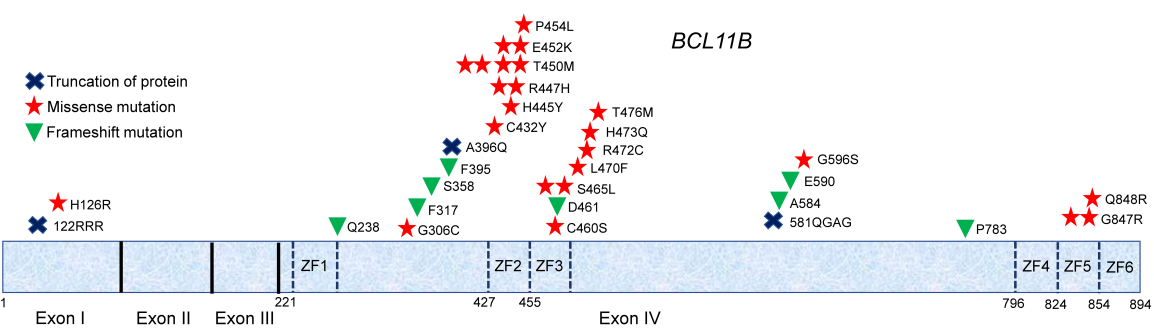

(B)

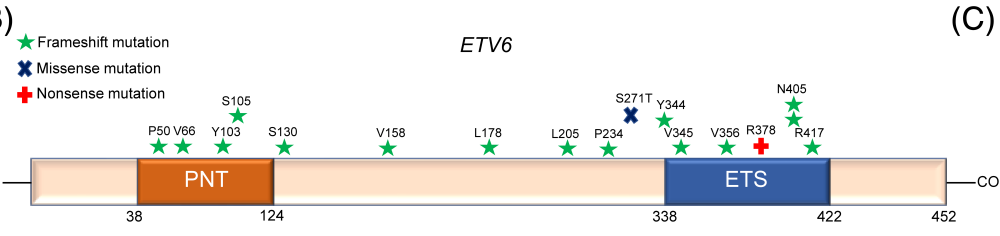

(C)

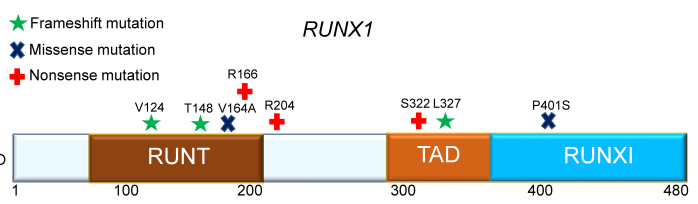

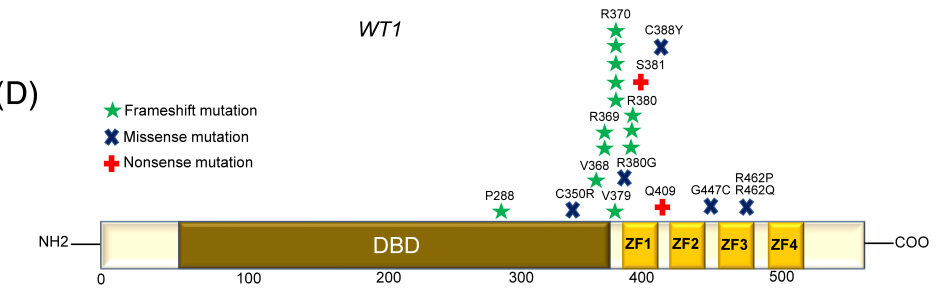

$(\mathrm{E})$

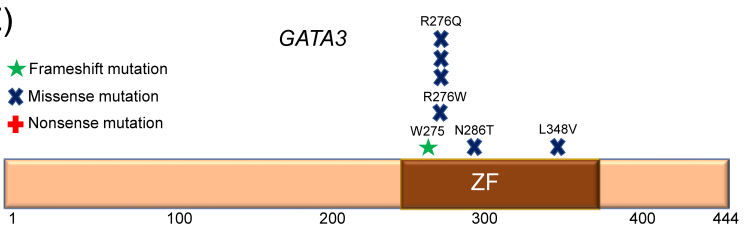

FIGURE 2 Schematic representation showing point mutations in the transcription factors in T-ALL. A, The zinc-finger domains of BCL11B, responsible for DNA-binding, are mutated across different subgroups of T-ALL patients. The majority of the mutations are missense/frameshift mutations, which abrogate the binding of this transcription factor to DNA. B, ETV6 harbors mutation, especially in the PNT (homodimerization) and ETS (DNA-binding) domains, the majority of which are frameshift mutations. C-E, Frameshift and missense mutations are predominantly present in RUNX1 (C), WT1 (D), and GATA3 (E), which abrogates DNA binding activity [Color figure can be viewed at wileyonlinelibrary.com]

\subsection{2 | ETV6}

The ETV6 (or TEL) gene encodes a transcriptional repressor with two functional domains, a C-terminal DNA-binding domain (ETS domain) and an N-terminal homodimerization domain (PNT domain). ${ }^{58}$ The homodimerization of ETV6 is indispensable for its transcriptional repression activity. The repression of target genes by ETV6 is vital in the regulation of cell growth, differentiation, and hematopoiesis. ${ }^{59,60}$

ETV6 is frequently altered in leukemia owing to its participation in various translocations, two of the well-known players being RUNX1 and $A B L 1 / 2{ }^{61,62}$ ETV6 also undergoes frequent mutation/deletion in $8 \%$ of pediatric T-ALL and $14 \%$ of adult T-ALL (Figure $2 B$ ). ${ }^{6}$ In immature T-ALLs, $80 \%$ of ETV6 mutant cases showed concomitant mutations in NOTCH1, hinting at a specific interaction between the two oncogenic proteins in the pathogenesis of immature T-ALL. ${ }^{63}$ Thus, mutational inactivation of ETV6 cooperates with oncogenic mutations in other genetic factors like RUNX1 (8\%-10\%), GATA3 (3\%-5\%), WT1 (11\%-19\%), BCL11B (9\%-16\%) to transform preleukemic cells to leukemic cells (Figure 2C-E). ${ }^{6,52}$

\section{4 | EPIGENETIC MUTATIONS IN T-ALL}

Besides the genomic alterations in leukemia, the disruption of the epigenomic homeostasis in $T$ cells plays a significant role in the disease progression of T-ALL. In a recent study, T-ALL was found to be among the cancers with the highest frequency of mutations in genes involved in regulating the epigenome. ${ }^{64}$ The epigenetic modifications mainly comprise DNA methylation, histone modifications, nucleosome remodeling, and so forth.

\subsection{DNA methylation and demethylation}

The DNA methyltransferases DNMT1, DNMT3A, and DNMT3B set up the DNA methylation pattern in humans by covalent addition of methyl groups to cytosine, which is part of the CpG dinucleotides. ${ }^{65}$ DNMT3A and DNMT3B are required for de novo methylation and, in cooperation with DNMT1, maintain the methylation marks in the genome. ${ }^{66}$ Around $4 \%$ to $18 \%$ of T-ALL cases harbor mutations in DNMT3A, associated with a poor prognosis and shorter disease-free survival $^{52,67}$ (Figure 3A and Table 1), with R882H being the most frequent "hotspot" mutation. ${ }^{68}$ Whole-exome sequencing identified a high rate of DNMT3A mutations (16\%) in a high-risk subgroup of adult patients with ETP-ALL ${ }^{69}$ making it an ideal prognostic marker. On the contrary, pediatric T-ALL patients harbor infrequent DNMT3A mutations (1.4\%). ${ }^{70}$ In fact, analysis of a large cohort of T-ALL patients using NGS approach correlated DNMT3A mutation with older age, immature leukemia, lower remission rates, and increased incidence of relapse. $^{71}$

Therapies targeting the majorly altered/mutated pathways in cancer treatment often undergo clinical failure due to cooperative 
(A)<smiles>Nc1cc[nH]c(=O)n1</smiles>

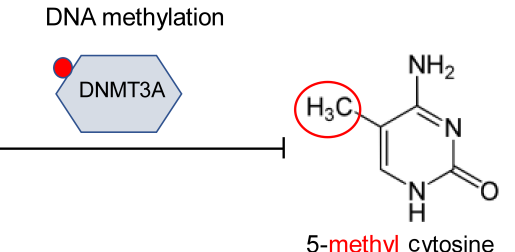

(C)

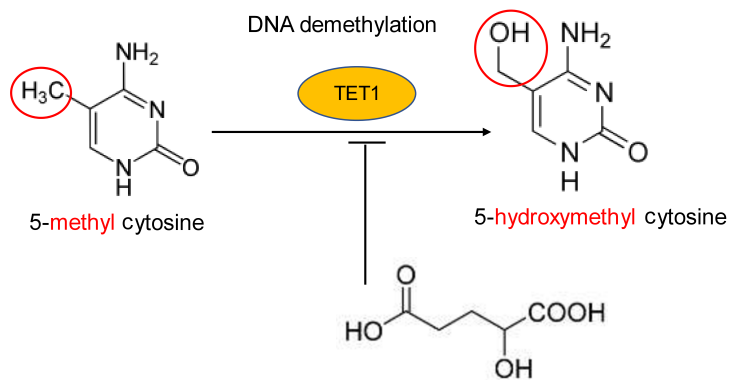

D2HG, Oncometabolite

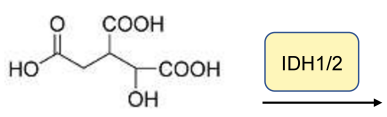

Isocitrate

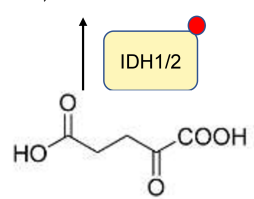

a-KG

5-methyl Cytosine

5-hydroxymethyl Cytosine

FIGURE 3 Schematic representation of genomic alteration in the epigenetic regulators found in T-ALL. A, DNMT3A is responsible for DNA methylation of cytosines, which are part of CpG dinucleotides. Mutation in DNMT3A leads to loss of methyltransferase activity and subsequent hypomethylation of $\mathrm{CpG}$ islands. B. The TET enzymes catalyze the conversion of methylated cytosine to 5-hydroxymethyl cytosine, which promotes DNA demethylation. TET1 mutations blocks this action, leading to silencing of active genes, for example, tumor suppressors. C, Mutations in IDH1/2 inhibit the activity of TET enzymes via the production of the oncometabolite 2-hydroxyglutarate (D2HG). Red circles indicate point mutations [Color figure can be viewed at wileyonlinelibrary.com]

oncogenic lesions from other genes. One such example is the failure of targeted therapies against NOTCH1-driven T-ALL due to recurrent mutagenic events in DNMT3A. Kramer et al showed that in mouse models, Dnmt3a loss-of-function cooperates with Notch1 gain-offunction to drive an aggressive T-ALL. ${ }^{72}$

Mutations disrupt the balance in the epigenetic homeostasis in TET enzymes, which catalyze the conversion of methylated cytosine to 5-hydroxymethyl-cytosine, promoting DNA demethylation. ${ }^{73}$ TET1 mutations have been reported in $6 \%$ to $14 \%$ of T-ALLs (Figure $3 \mathrm{~B}$ ). ${ }^{74}$ Strikingly, the interaction between inactivated TET2 and $D N M T 3 A^{R 882 H}$ alters the global DNA methylation landscape, compromising the function of several tumor suppressors in the mouse model of T-ALL. ${ }^{75}$ TET enzymes require 2-oxoglutarate for its function; one of the sources is isocitrate dehydrogenases (IDH) that catalyzes the decarboxylation of isocitrate to 2-oxoglutarate. ${ }^{76}$ In fact, a mutation in IDH1 and IDH2 reported in $2 \%$ to $10 \%$ of early immature adult T-ALL subgroup confers a worse clinical outcome (Figure 3C). ${ }^{10,63,77}$ Subsequent gain-of-function activity of the enzyme leads to NADPH-dependent reduction of $\alpha$-ketoglutarate $(\alpha-K G)$ to the oncometabolite, 2-hydroxyglutarate. ${ }^{77}$ However, the implications of such cooperative oncogenic mutations in T-ALL disease progression need to be explored further.

\section{2 | Posttranslational histone modifications}

The histones undergo a multitude of posttranslational modifications, including lysine acetylation, serine, and threonine phosphorylation, lysine and arginine methylation, lysine ubiquitinylation, SUMOylation, and so forth. HATs (histone acetyltransferase) and
HDACs (histone deacetylases) regulate the acetylation and deacetylation of core histone proteins and nonhistone proteins like MYB, E2F1, TP53, and RB1, respectively, thereby triggering gene transcription on receiving the proper cue. ${ }^{78}$ However, this balance is disrupted when the epigenetic regulators undergo somatic mutation during cancer initiation. In pediatric and adult T-ALL, the histone acetyltransferase EP300 undergoes mutation in $\sim 2 \%$ of the cases whereas HDAC5 and HDAC7 are mutated in about $1 \%$ and $4 \%$ cases, respectively. ${ }^{74}$ Mice with double knockout of Hdac1/2 develop a pathological diseased state characterized by an enlarged spleen and thymus. Infiltration of immature $\mathrm{T}$ cells into the lymphoid and nonlymphoid tissues in the knockout mice leads to neoplastic transformation and chromosomal instability. ${ }^{79}$

Similarly, the significance of transcriptional gene repression mediated by the Polycomb repressive complex 2 (PRC2) was elucidated following the loss of function mutations of the core components of this complex (EZH2, SUZ12, and EED) in both pediatric ${ }^{80}$ and adult TALL. ${ }^{81}$ The PRC2 component, EZH2, along with SUZ12, mediates gene silencing by catalyzing di- and tri-methylation of Lys 27 on histone $\mathrm{H} 3$ $(\mathrm{H} 3 \mathrm{~K} 27 \mathrm{me} 2 / 3){ }^{82}$ Mutations in the SET domain of EZH2, responsible for its $\mathrm{N}$-methyltransferase activity ${ }^{80}$ leads to spontaneous development of T-ALL in mice carrying Cre-mediated deletion of the SET domain of EZH2 ${ }^{83}$ Therefore, a loss of tumor-suppressive function of EZH2 can account for its low expression and frequent alteration. ${ }^{83} \mathrm{~A}$ study by Ntziachristos et al showed that loss of function of PRC2 components leads to T-cell malignancy initiation, which progresses into T-ALL when concomitant NOTCH1 mutation triggers the eviction of the PRC2 complex near NOTCH1 target genes, leading to loss of $\mathrm{H} 3 \mathrm{~K} 27 \mathrm{me} 3$ mark and activation of a host of genes with oncogenic potential. $^{81}$ 
Counteracting the activity of the PRC2 complex is the histone H3K27me3 demethylase, an ubiquitously transcribed X (UTX) chromosome tetratricopeptide repeat protein (KDM6A). ${ }^{84}$ Exome sequencing of a cohort of adult T-ALL patients and cell lines identified somatic mutations ( $4.5 \%$ ) in the UTX/KDM6A gene. ${ }^{85}$ UTX was identified as the first $X$-linked tumor suppressor in T-ALL which escapes chromosome $\mathrm{X}$-inactivation in female T-ALL patients, thus, explaining the skewed gender distribution of inactivating somatic mutations. ${ }^{86}$ Loss of Utx accelerates leukemia onset in a Notch1-driven T-ALL mouse model. ${ }^{87}$ Surprisingly, in TAL1-positive T-ALL, it plays an oncogenic role by promoting TAL1-specific leukemic gene expression program. ${ }^{88}$ This subtype-specific differential role of UTX makes it a potential candidate for epigenetic drug targeting. In fact, inhibition of UTX with the H3K27 demethylase inhibitor GSK-J4 selectively eliminates TAL1-positive leukemic cells in both cell culture and xenograft models of patient-derived leukemia. ${ }^{88}$

In contrast, the $\mathrm{H} 3 \mathrm{~K} 27$ histone demethylase, JumonjiD3 (JMJD3) (or KDM6B) is required for the seeding and maintenance of T-ALL through interaction with NOTCH1. Genetic ablation of Jmjd3 in T-ALL diminishes leukemic cells in the peripheral blood, and minimizes the infiltration of leukemic cells into the spleen and liver. ${ }^{89}$

Along with histone methyltransferase and demethylases, inactivating mutations in the deubiquitylating enzyme, USP7 (Ubiquitin-specificprocessing protease 7) destabilizes the tumor suppressors, p53, DNMT1, PTEN and histone H2B. ${ }^{64,90}$ The mutations reside mostly at the binding interface between the catalytic domain of USP7 and ubiquitin, thereby interfering with the deubiquitinase activity of the enzyme. ${ }^{64}$ However, the somatic loss of function mutations was reported only in $8 \%$ of pediatric T-ALL and rarely in adult T-ALL cases. ${ }^{64}$ Nevertheless, malignant transformation of immature $T$ cells due to loss of a deubiquitylating enzyme warrants further investigation.

\section{3 | PHF6: An epigenetic regulator?}

The role of HATs, HDACs, PRC complex, and so forth as epigenetic modifiers have been well documented in leukemia. However, growing evidence suggests the role of plant homeodomain finger 6 (PHF6) gene, initially discovered as the causal gene behind the $\mathrm{X}$-linked disorder, Borjeson-Forssman-Lehmann syndrome, as an epigenetic modifier. ${ }^{91} \mathrm{PHD}$ domain-containing proteins are known to recognize methylation marks on histone, implicating the role of PHF6 in chromatin structure reorganization. ${ }^{92}$

A study by Vlierberghe et al showed that the PHF6 gene harbors inactivating mutations and deletions in $16 \%$ to $19 \%$ of pediatric and $30 \%$ to $38 \%$ of adult primary T-ALL cases (Figure S4). ${ }^{93}$ Loss of function of this tumor suppressor gene was significantly associated with leukemogenesis driven by aberrant expression of the transcription factor oncogenes, TLX1 and TLX3 ${ }^{93}$ Thus, PHF6 can be called a new X-linked tumor suppressor in T-ALL, inactivation of which leads to aberrant expression of oncogenic transcription factors in leukemia. $^{93}$
In summary, along with these epigenetic regulators, mutation in several other histone methylases, demethylases, acetylases, such as SETD2, MLL complex, NSD2 disrupt the epigenetic equilibrium in T-ALL. ${ }^{74}$

\section{5 | MECHANISTIC INSIGHT INTO THE GENESIS OF MUTATION IN T-ALL}

The deleterious point mutations in genes associated with DNA repair, signaling networks, transcription factors, epigenetic regulators, and so forth initiates a chain of events that activates the oncogenic programs in T-ALL. A recent study indicated the formation of non-B DNA structures as a major determinant of mutagenesis, which increases the likelihood of recurrent somatic mutations in the genome. ${ }^{94}$ Several reports suggest that one of the major causes of genomic instability is the occurrence of non-B DNA structures in the genome. ${ }^{95-98}$ Formation of noncanonical structures like G-quadruplexes, triplexes, cruciform are favored in several genes due to the abundance of repetitive sequences in the eukaryotes. ${ }^{99-102}$ Interestingly, such altered structures in the genome have been mapped to regions of patient chromosomal breakpoints in the majority of genes deregulated in lymphoid cancers, for example, BCL2 major breakpoint region associated with $\mathrm{t}$ $(14 ; 18)$ translocation in follicular lymphomas. ${ }^{95,98,103-105}$ Similarly, G-quadruplex motifs have been reported in c-MYC, c-KIT, VEGF, HIF1 $\alpha$, and KRAS, associated with different types of chromosomal aberrations. ${ }^{95,106-110}$ In addition to G-quadruplex, Palindromic AT Rich Repeat (PATRR) and cruciform DNA structure have also been implicated in $\mathrm{t}(11 ; 22){ }^{111}$

$t(10 ; 14)$ translocation, associated with $5 \%$ to $10 \%$ of T-ALL cases, involves a reciprocal translocation between chromosomes 10 and 14, wherein the HOX11 gene juxtaposes with the TCR locus, resulting in altered expression of HOX11 in T cells. ${ }^{97,112}$ The presence of two G-quadruplex motifs, capable of folding into G4 structure, flanking either side of HOX11 breakpoint regions suggests a potential role of G-quadruplex formation and increased frequency of chromosomal translocation. ${ }^{97,103}$

Additionally, misrecognition of certain chromosomal fragile sites, LMO2 (t(11;14) (p13; q11)), Ttg-1 (t (11;14) (p15; q11)), and Hox11 (t $(10 ; 14)$ (q24; q11)) by the RAG complex serves as one of the major determining factors behind the frequency of these translocations in TALL. ${ }^{113}$ Analysis of several human translocation breakpoints at non-lg genes, including $B C L 2, B C L 1$, and $E 2 A$ reveals an additional mechanism of genetic rearrangement around the breakpoint regions in several leukemias and lymphomas. ${ }^{114}$ The breakpoints showed clustering around CpG sites, which was more prominent in pro-/pre-B stages and drastically reduced in other mature cell types. The increased frequency of translocation around the "CpG hotspot" region can be explained by the sequential action of AID and RAG, wherein demethylation of CpG regions by AID generates T:G mismatches, prone to cleavage by RAG endonuclease, before repair can be completed. ${ }^{114}$ This double-strand break event leads to frequent translocations observed in B cell lymphomas and leukemia. Besides, AID is also capable of generating point mutations and other genomic aberrations by binding to single-stranded 


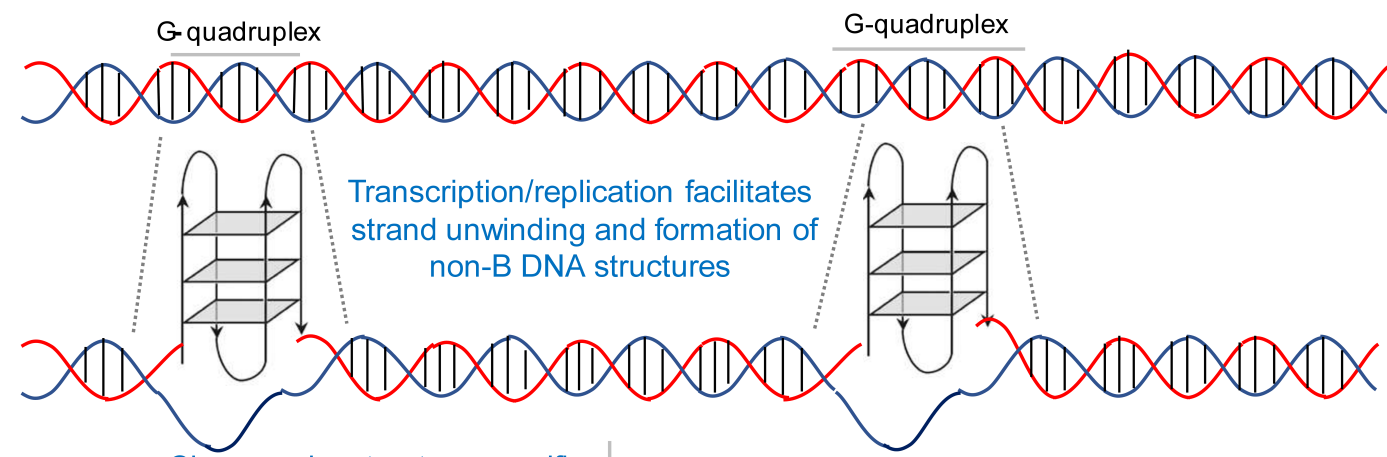

Cleavage by structure-specific endonuclease such as RAGs

Deamination of cytosines by AID
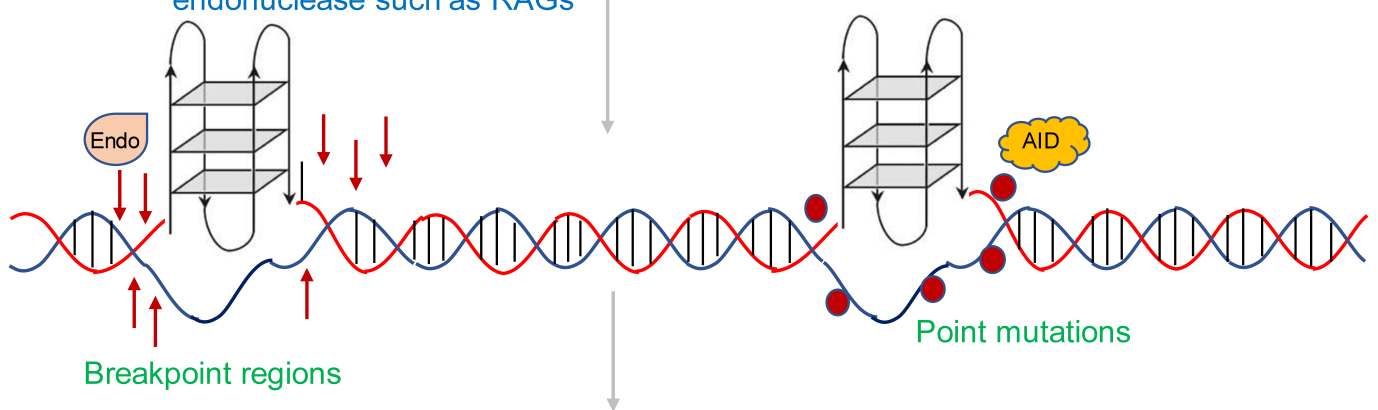

Transcription, replication arrest and faulty repair

FIGURE 4 The plausible mechanism behind the introduction of genomic lesions in leukemia/lymphoma. Inside the cell, unwinding of DNA takes place during transcription/ replication/ recombination, and so forth facilitating the formation of different non-B DNA structures like Gquadruplex, triplex, cruciform, and so forth. The formation of such noncanonical structures in the genome makes it prone to cleavage by structure-specific endonuclease like RAGs or deamination by deaminases like AID. This results in genetic mutations, single-strand, and doublestranded breaks, which ultimately culminates into fragile breakpoint regions. Activation of faulty DNA repair pathways further contributes to the disease biology and pathogenesis of leukemia/lymphoma. Arrow heads indicate breakpoint regions, while red circles indicate point mutations [Color figure can be viewed at wileyonlinelibrary.com]

regions of non-Ig genes for example, p53, c-MYC, KRAS, SMAD4, BCL6 in different types of cancer. ${ }^{115-118}$ However, more studies are required in this direction to elucidate the mechanism of generation of point mutations in T-ALL (Figure 4).

\section{6 | CONCLUSION}

The genetic and epigenetic aberrations that accumulate in the genome play a significant role in altering the genetics of childhood and adult TALL. Point mutations, specifically the missense and frameshift mutations, can lead to loss of functionality or gain of the oncogenic activity of different genes. This sets the stage for a series of different oncogenic events transforming normal T cells to leukemic cells. While the role of genomic lesions behind the pathogenesis of T-ALL is quite well studied, alteration of the chromatin landscape due to inactivation of histone methylases, demethylases, ubiquitinases, such as DNMTs, $K D M 6 A / B$, USP7, and so forth warrants further investigation. Decoding the mutation spectrum of these genes in different subtypes of T-ALL would pave the way for the development of "new-age" epigenetic drugs leading to a better treatment outcome. One of the plausible mechanisms behind the generation of these mutations is the formation of non-B DNA structures in the vicinity of the breakpoint regions. ${ }^{95,98,105}$ Likewise, an in-depth analysis of the breakpoint regions is imperative to decipher the seeding events behind the initiation of the deleterious genetic rearrangements in T-ALL.

\section{7 | FUTURE DIRECTIONS}

Mutagenic events contribute significantly to the disease biology of hematological and nonhematological malignancies. However, in leukemia and lymphoma, both chromosomal translocations and driver mutations are the leading players behind altering its genetic and epigenetic profile. While the molecular mechanism behind chromosomal translocations is well explored, the potential reasons behind the induction of driver mutations in T-ALL needs more attention. This is particularly important in epigenetic regulators, mutations in which are capable of altering the chromatin landscape, organization, and transcriptional status of cancer-related genes. Besides, driver genes harboring a distinct mutation pattern can also serve as biomarkers in leukemia. Genetic and epigenetic biomarkers can predict disease prognosis, treatment outcome, and cancer initiation. ${ }^{119}$ Thus, identifying the driver mutations in putative genes involved in leukemogenesis and determining the molecular mechanism behind their origin is pivotal for the development of targeted therapies in leukemia. 


\section{ACKNOWLEDGMENTS}

We thank Meghana Manjunath, Dipayan Ghosh, and other members of SCR laboratory for critical reading and comments on the paper. This work was supported by grants from DBT-COE (BT/PR13458/ COE/34/33/2015), Glue-Grant (BT/PR23078/MED/29/1253/2017), DBT-IISc partnership program (BT/PR27952-INF/22/212/2018) to Sathees C. Raghavan. Urbi Roy is supported by Senior Research Fellowship (SRF) from IISc.

\section{CONFLICT OF INTEREST}

Authors disclose that there is no conflict of interest.

\section{ORCID}

Sathees C. Raghavan (D) https://orcid.org/0000-0003-3003-1417

\section{REFERENCES}

1. Parkin DM, Bray F, Ferlay J, Pisani P. Global cancer statistics, 2002. CA Cancer J Clin. 2005;55:74-108.

2. Ribeiro D, Melão A, Barata JT. IL-7R-mediated signaling in T-cell acute lymphoblastic leukemia. Adv Biol Regul. 2013;53:211-222.

3. Terwilliger T, Abdul-Hay M. Acute lymphoblastic leukemia: a comprehensive review and 2017 update. Blood Cancer J. 2017;7:e577.

4. Vardiman JW, Thiele J, Arber DA, et al. The 2008 revision of the World Health Organization (WHO) classification of myeloid neoplasms and acute leukemia: rationale and important changes. Blood. 2009;114:937-951.

5. Chen $B$, Jiang $L$, Zhong $M-L$, et al. Identification of fusion genes and characterization of transcriptome features in T-cell acute lymphoblastic leukemia. Proc Natl Acad Sci U S A. 2018;115:373-378.

6. Girardi T, Vicente C, Cools J, De Keersmaecker K. The genetics and molecular biology of T-ALL. Blood. 2017;129:1113-1123.

7. Stengel A, Schnittger S, Weissmann S, et al. TP53 mutations occur in $15.7 \%$ of ALL and are associated with MYC-rearrangement, low hypodiploidy, and a poor prognosis. Blood. 2014;124:251-258.

8. Weng AP, Ferrando AA, Lee $W$, et al. Activating mutations of NOTCH1 in human T cell acute lymphoblastic leukemia. Science. 2004;306:269-271.

9. Oliveira ML, Akkapeddi P, Ribeiro D, Melão A, Barata JT. IL-7Rmediated signaling in T-cell acute lymphoblastic leukemia: an update. Adv Biol Regul. 2019;71:88-96.

10. Van Vlierberghe $P$, Ambesi-Impiombato A, De Keersmaecker K, et al. Prognostic relevance of integrated genetic profiling in adult T-cell acute lymphoblastic leukemia. Blood. 2013;122:74-82.

11. Bartram I, Gökbuget N, Schlee C, et al. Low expression of T-cell transcription factor BCL11b predicts inferior survival in adult standard risk T-cell acute lymphoblastic leukemia patients. J Hematol Oncol. 2014:7:51.

12. Koch U, Radtke F. Mechanisms of T cell development and transformation. Annu Rev Cell Dev Biol. 2011;27:539-562.

13. Martins VC, Busch K, Juraeva D, et al. Cell competition is a tumour suppressor mechanism in the thymus. Nature. 2014;509:465-470.

14. Pui JC, Allman D, Xu L, et al. Notch1 expression in early lymphopoiesis influences B versus $\mathrm{T}$ lineage determination. Immunity. 1999;11:299-308.

15. Germain RN. T-cell development and the CD4-CD8 lineage decision. Nat Rev Immunol. 2002;2:309-322.

16. Robey E, Fowlkes BJ. Selective events in T cell development. Annu Rev Immunol. 1994;12:675-705.

17. Kumar BV, Connors TJ, Farber DL, Cell Development HT. Localization, and function throughout life. Immunity. 2018;48:202-213.
18. Gourley TS, Wherry EJ, Masopust D, Ahmed R. Generation and maintenance of immunological memory. Semin Immunol. 2004;16: 323-333.

19. Weber BN, Chi AW-S, Chavez A, et al. A critical role for TCF-1 in T-lineage specification and differentiation. Nature. 2011;476: 63-68.

20. Rothenberg EV. Transcriptional control of early T and B cell developmental choices. Annu Rev Immunol. 2014;32:283-321.

21. Rivlin N, Brosh R, Oren M, Rotter V. Mutations in the p53 tumor suppressor gene: important milestones at the various steps of tumorigenesis. Genes Cancer. 2011;2:466-474.

22. Cheng J, Haas M. Frequent mutations in the p53 tumor suppressor gene in human leukemia T-cell lines. Mol Cell Biol. 1990;10:55025509.

23. Hof J, Krentz S, van Schewick C, et al. Mutations and deletions of the TP53 gene predict nonresponse to treatment and poor outcome in first relapse of childhood acute lymphoblastic leukemia. J Clin Oncol. 2011;29:3185-3193.

24. Jonveaux P, Berger R. Infrequent mutations in the P53 gene in primary human T-cell acute lymphoblastic leukemia. Leukemia. 1991;5: 839-840.

25. Hsiao $\mathrm{MH}, \mathrm{Yu}$ AL, Yeargin J, Ku D, Haas M. Nonhereditary p53 mutations in T-cell acute lymphoblastic leukemia are associated with the relapse phase. Blood. 1994;83:2922-2930.

26. Diccianni MB, Yu J, Hsiao M, Mukherjee S, Shao LE, Yu AL. Clinical significance of p53 mutations in relapsed T-cell acute lymphoblastic leukemia. Blood. 1994;84:3105-3112.

27. Chiaretti S, Brugnoletti F, Tavolaro S, et al. TP53 mutations are frequent in adult acute lymphoblastic leukemia cases negative for recurrent fusion genes and correlate with poor response to induction therapy. Haematologica. 2013;98:e59-e61.

28. Agirre X, Novo FJ, Calasanz MJ, et al. TP53 is frequently altered by methylation, mutation, and/or deletion in acute lymphoblastic leukaemia. Mol Carcinogen. 2003;38(4):201-208.

29. Oren M, Rotter V. Mutant p53 gain-of-function in cancer. Cold Spring Harb Perspect Biol. 2010;2:a001107.

30. Lozano G. Mouse models of p53 functions. Cold Spring Harb Perspect Biol. 2010;2:a001115.

31. Kenzelmann Broz D, Attardi LD. In vivo analysis of p53 tumor suppressor function using genetically engineered mouse models. Carcinogenesis. 2010;31:1311-1318.

32. Hsiao M, Low J, Dorn E, et al. Gain-of-function mutations of the p53 gene induce lymphohematopoietic metastatic potential and tissue invasiveness. Am J Pathol. 1994;145:702-714.

33. Ceccaldi R, Sarangi P, D'Andrea AD. The Fanconi anaemia pathway: new players and new functions. Nat Rev Mol Cell Biol. 2016;17: 337-349.

34. Rosenberg PS, Greene MH, Alter BP. Cancer incidence in persons with Fanconi anemia. Blood. 2003;101:822-826.

35. Pouliot GP, Degar J, Hinze L, et al. Fanconi-BRCA pathway mutations in childhood T-cell acute lymphoblastic leukemia. PLoS One. 2019;14:e0221288.

36. Friedman LS, Thistlethwaite FC, Patel KJ, et al. Thymic lymphomas in mice with a truncating mutation in Brca2. Cancer Res. 1998;58: 1338-1343.

37. Connor F, Bertwistle D, Mee PJ, et al. Tumorigenesis and a DNA repair defect in mice with a truncating Brca2 mutation. Nat Genet. 1997; 17:423-430

38. Patel $\mathrm{KJ}, \mathrm{Yu} \mathrm{VP}$, Lee $\mathrm{H}$, et al. Involvement of Brca2 in DNA repair. Mol Cell. 1998;1:347-357.

39. Yu VP, Koehler M, Steinlein C, et al. Gross chromosomal rearrangements and genetic exchange between nonhomologous chromosomes following BRCA2 inactivation. Genes Dev. 2000;14: 1400-1406. 
40. Hirsch B, Shimamura A, Moreau L, et al. Association of biallelic BRCA2/FANCD1 mutations with spontaneous chromosomal instability and solid tumors of childhood. Blood. 2004;103:2554-2559.

41. Van Vlierberghe P, Ferrando A. The molecular basis of $T$ cell acute lymphoblastic leukemia. J Clin Invest. 2012;122:3398-3406.

42. Belver L, Ferrando A. The genetics and mechanisms of $T$ cell acute lymphoblastic leukaemia. Nat Rev Cancer. 2016;16:494-507.

43. Liu Y, Easton J, Shao Y, et al. The genomic landscape of pediatric and young adult T-lineage acute lymphoblastic leukemia. Nat Genet. 2017;49:1211-1218.

44. Mazzucchelli R, Durum SK. Interleukin-7 receptor expression: intelligent design. Nat Rev Immunol. 2007;7:144-154.

45. Peschon JJ, Morrissey PJ, Grabstein KH, et al. Early lymphocyte expansion is severely impaired in interleukin 7 receptor-deficient mice. J Exp Med. 1994;180:1955-1960.

46. Canté-Barrett K, Spijkers-Hagelstein JAP, Buijs-Gladdines JGCAM, et al. MEK and PI3K-AKT inhibitors synergistically block activated IL7 receptor signaling in T-cell acute lymphoblastic leukemia. Leukemia. 2016;30:1832-1843

47. Oliveira ML, Akkapeddi $P$, Alcobia I, et al. From the outside, from within: biological and therapeutic relevance of signal transduction in T-cell acute lymphoblastic leukemia. Cell Signal. 2017;38:10-25.

48. Tanigaki K, Honjo T. Regulation of lymphocyte development by Notch signaling. Nat Immunol. 2007;8:451-456.

49. Malecki MJ, Sanchez-Irizarry C, Mitchell JL, et al. Leukemiaassociated mutations within the NOTCH1 heterodimerization domain fall into at least two distinct mechanistic classes. Mol Cell Biol. 2006;26:4642-4651.

50. Thompson BJ, Buonamici S, Sulis ML, et al. The SCFFBW7 ubiquitin ligase complex as a tumor suppressor in T cell leukemia. J Exp Med. 2007;204:1825-1835.

51. Ferrando AA. The role of NOTCH1 signaling in T-ALL. Hematology Am Soc Hematol Educ Program. 2009;2009:353-361.

52. Neumann M, Vosberg S, Schlee $C$, et al. Mutational spectrum of adult T-ALL. Oncotarget. 2015;6:2754-2766.

53. Liu P, Li P, Burke S. Critical roles of Bcl11b in T-cell development and maintenance of T-cell identity. Immunol Rev. 2010;238:138-149.

54. Kominami R. Role of the transcription factor Bcl11b in development and lymphomagenesis. Proc Jpn Acad Ser B Phys Biol Sci. 2012;88: 72-87.

55. Li P, Burke S, Wang J, et al. Reprogramming of $T$ cells to natural killer-like cells upon Bcl11b deletion. Science. 2010;329:85-89.

56. Gutierrez A, Kentsis A, Sanda T, et al. The BCL11B tumor suppressor is mutated across the major molecular subtypes of T-cell acute lymphoblastic leukemia. Blood. 2011;118:4169-4173.

57. MacLeod RAF, Nagel S, Kaufmann M, Janssen JWG, Drexler HG. Activation of HOX11L2 by juxtaposition with $3^{\prime}-B C L 11 B$ in an acute lymphoblastic leukemia cell line (HPB-ALL) with $t(5 ; 14)(q 35 ; q 32.2)$. Genes Chromosomes Cancer. 2003;37:84-91.

58. Lopez RG, Carron C, Oury C, Gardellin P, Bernard O, Ghysdael J. TEL is a sequence-specific transcriptional repressor. J Biol Chem. 1999;274:30132-30138.

59. Wang LC, Swat W, Fujiwara Y, et al. The TEL/ETV6 gene is required specifically for hematopoiesis in the bone marrow. Genes Dev. 1998; 12:2392-2402.

60. Fenrick R, Wang L, Nip J, et al. TEL, a putative tumor suppressor, modulates cell growth and cell morphology of ras-transformed cells while repressing the transcription of stromelysin-1. Mol Cell Biol. 2000;20:5828-5839.

61. Golub TR, Barker GF, Bohlander SK, et al. Fusion of the TEL gene on $12 \mathrm{p} 13$ to the AML1 gene on 21q22 in acute lymphoblastic leukemia. Proc Natl Acad Sci U S A. 1995;92:4917-4921.

62. De Braekeleer E, Douet-Guilbert N, Morel F, Le Bris M-J, Basinko A, De Braekeleer M. ETV6 fusion genes in hematological malignancies: a review. Leuk Res. 2012;36:945-961.
63. Van Vlierberghe P, Ambesi-Impiombato A, Perez-Garcia A, et al. ETV6 mutations in early immature human T cell leukemias. J Exp Med. 2011;208:2571-2579.

64. Huether R, Dong L, Chen X, et al. The landscape of somatic mutations in epigenetic regulators across 1,000 paediatric cancer genomes. Nat Commun. 2014;5:3630.

65. Robertson KD. DNA methylation and chromatin-unraveling the tangled web. Oncogene. 2002;21:5361-5379.

66. Jones PA, Liang G. Rethinking how DNA methylation patterns are maintained. Nat Rev Genet. 2009;10:805-811.

67. Roller A, Grossmann V, Bacher U, et al. Landmark analysis of DNMT3A mutations in hematological malignancies. Leukemia. 2013; 27:1573-1578.

68. Huang $\mathrm{X}, \mathrm{Ma} \mathrm{D}$, Dong $\mathrm{W}$, et al. Gene expression profiling of the DNMT3A R882 mutation in acute leukemia. Oncol Lett. 2013;6: 268-274.

69. Neumann $\mathrm{M}$, Heesch $\mathrm{S}$, Schlee $\mathrm{C}$, et al. Whole-exome sequencing in adult ETP-ALL reveals a high rate of DNMT3A mutations. Blood. 2013;121:4749-4752.

70. Szarzyńska-Zawadzka B, Kosmalska M, Sędek $Ł$, et al. Cost-effective screening of DNMT3A coding sequence identifies somatic mutation in pediatric T-cell acute lymphoblastic leukemia. Eur J Haematol. 2017;99:514-519.

71. Bond J, Touzart A, Leprêtre S, et al. DNMT3A mutation is associated with increased age and adverse outcome in adult T-cell acute lymphoblastic leukemia. Haematologica. 2019;104:1617-1625.

72. Kramer AC, Kothari A, Wilson WC, et al. Dnmt3a regulates T-cell development and suppresses T-ALL transformation. Leukemia. 2017; 31:2479-2490.

73. Guo JU, Su Y, Zhong C, Ming G, Song H. Hydroxylation of 5-methylcytosine by TET1 promotes active DNA demethylation in the adult brain. Cell. 2011;145:423-434.

74. Peirs S, Van der Meulen J, Van deaaa Walle I, et al. Epigenetics in Tcell acute lymphoblastic leukemia. Immunol Rev. 2015;263:50-67.

75. Scourzic L, Couronné L, Pedersen MT, et al. DNMT3A(R882H) mutant and Tet2 inactivation cooperate in the deregulation of DNA methylation control to induce lymphoid malignancies in mice. Leukemia. 2016;30:1388-1398.

76. Solary E, Bernard OA, Tefferi A, Fuks F, Vainchenker W. The teneleven Translocation-2 (TET2) gene in hematopoiesis and hematopoietic diseases. Leukemia. 2014;28:485-496.

77. Zhang $\mathrm{Y}$, Wei H, Tang K, et al. Mutation analysis of isocitrate dehydrogenase in acute lymphoblastic leukemia. Genet Test Mol Biomarkers. 2012;16:991-995.

78. Wang F, Marshall CB, Ikura M. Transcriptional/epigenetic regulator $\mathrm{CBP} / \mathrm{p} 300$ in tumorigenesis: structural and functional versatility in target recognition. Cell Mol Life Sci. 2013;70:3989-4008.

79. Dovey OM, Foster CT, Conte N, et al. Histone deacetylase 1 and 2 are essential for normal T-cell development and genomic stability in mice. Blood. 2013;121:1335-1344.

80. Zhang J, Ding L, Holmfeldt L, et al. The genetic basis of early T-cell precursor acute lymphoblastic leukaemia. Nature. 2012;481: 157-163.

81. Ntziachristos $P$, Tsirigos A, Van Vlierberghe $P$, et al. Genetic inactivation of the polycomb repressive complex 2 in T cell acute lymphoblastic leukemia. Nat Med. 2012;18:298-301.

82. Surface LE, Thornton SR, Boyer LA. Polycomb group proteins set the stage for early lineage commitment. Cell Stem Cell. 2010;7: 288-298.

83. Simon C, Chagraoui J, Krosl J, et al. A key role for EZH2 and associated genes in mouse and human adult T-cell acute leukemia. Genes Dev. 2012;26:651-656.

84. Agger $\mathrm{K}$, Cloos PAC, Christensen J, et al. UTX and JMJD3 are histone H3K27 demethylases involved in HOX gene regulation and development. Nature. 2007;449:731-734. 
85. De Keersmaecker K, Atak ZK, Li N, et al. Exome sequencing identifies mutation in CNOT3 and ribosomal genes RPL5 and RPL10 in T-cell acute lymphoblastic leukemia. Nat Genet. 2013;45:186-190.

86. Van der Meulen J, Sanghvi V, Mavrakis K, et al. The H3K27me3 demethylase UTX is a gender-specific tumor suppressor in T-cell acute lymphoblastic leukemia. Blood. 2015;125:13-21.

87. Pear WS, Aster JC, Scott ML, et al. Exclusive development of T cell neoplasms in mice transplanted with bone marrow expressing activated Notch alleles. J Exp Med. 1996;183:2283-2291.

88. Benyoucef A, Palii CG, Wang C, et al. UTX inhibition as selective epigenetic therapy against TAL1-driven T-cell acute lymphoblastic leukemia. Genes Dev. 2016;30:508-521.

89. Ntziachristos P, Tsirigos A, Welstead GG, et al. Contrasting roles of histone 3 lysine 27 demethylases in acute lymphoblastic leukaemia. Nature. 2014;514:513-517.

90. Felle $M$, Joppien $S$, Németh $A$, et al. The USP7/Dnmt1 complex stimulates the DNA methylation activity of Dnmt1 and regulates the stability of UHRF1. Nucleic Acids Res. 2011;39:8355-8365.

91. Lower KM, Turner G, Kerr BA, et al. Mutations in PHF6 are associated with Börjeson-Forssman-Lehmann syndrome. Nat Genet. 2002; 32:661-665.

92. Liu Z, Li F, Ruan K, et al. Structural and functional insights into the human Börjeson-Forssman-Lehmann syndrome-associated protein PHF6. J Biol Chem. 2014;289:10069-10083.

93. Van Vlierberghe P, Palomero T, Khiabanian H, et al. PHF6 mutations in T-cell acute lymphoblastic leukemia. Nat Genet. 2010;42:338-342.

94. Georgakopoulos-Soares I, Morganella S, Jain N, Hemberg M, NikZainal S. Noncanonical secondary structures arising from non-B DNA motifs are determinants of mutagenesis. Genome Res. 2018;28: 1264-1271.

95. Nambiar M, Goldsmith G, Moorthy BT, et al. Formation of a Gquadruplex at the BCL2 major breakpoint region of the $t(14 ; 18)$ translocation in follicular lymphoma. Nucleic Acids Res. 2011;39:936-948.

96. Nambiar M, Raghavan SC. Mechanism of fragility at BCL2 gene minor breakpoint cluster region during $\mathrm{t}(14 ; 18)$ chromosomal translocation. J Biol Chem. 2012;287:8688-8701.

97. Nambiar M, Srivastava M, Gopalakrishnan V, Sankaran SK, Raghavan SC. G-quadruplex structures formed at the HOX11 breakpoint region contribute to its fragility during $\mathrm{t}(10 ; 14)$ translocation in T-cell leukemia. Mol Cell Biol. 2013;33:4266-4281.

98. Raghavan SC, Swanson PC, Wu X, Hsieh C-L, Lieber MR. A non-BDNA structure at the $\mathrm{Bcl}-2$ major breakpoint region is cleaved by the RAG complex. Nature. 2004;428:88-93.

99. Mirkin SM. Discovery of alternative DNA structures: a heroic decade (1979-1989). Front Biosci. 2008;13:1064-1071.

100. Sen D, Gilbert W. Formation of parallel four-stranded complexes by guanine-rich motifs in DNA and its implications for meiosis. Nature. 1988;334:364-366.

101. Lilley DM. The inverted repeat as a recognizable structural feature in supercoiled DNA molecules. Proc Natl Acad Sci U S A. 1980;77: 6468-6472.

102. Frank-Kamenetskii MD, Mirkin SM. Triplex DNA structures. Annu Rev Biochem. 1995;64:65-95.

103. Katapadi VK, Nambiar M, Raghavan SC. Potential G-quadruplex formation at breakpoint regions of chromosomal translocations in cancer may explain their fragility. Genomics. 2012;100:72-80.

104. Nambiar M, Kari V, Raghavan SC. Chromosomal translocations in cancer. Biochim Biophys Acta. 2008;1786:139-152.

105. Raghavan SC, Swanson PC, Ma Y, Lieber MR. Double-strand break formation by the RAG complex at the bcl-2 major breakpoint region and at other non-B DNA structures in vitro. Mol Cell Biol. 2005;25: 5904-5919.

106. Inagaki $\mathrm{H}$, Ohye $\mathrm{T}$, Kogo $\mathrm{H}$, et al. Chromosomal instability mediated by non-B DNA: cruciform conformation and not DNA sequence is responsible for recurrent translocation in humans. Genome Res. 2009;19:191-198.

107. Wells RD. Non-B DNA conformations, mutagenesis and disease. Trends Biochem Sci. 2007;32:271-278.

108. Siddiqui-Jain A, Grand CL, Bearss DJ, Hurley LH. Direct evidence for a G-quadruplex in a promoter region and its targeting with a small molecule to repress c-MYC transcription. Proc Natl Acad Sci U S A. 2002;99:11593-11598.

109. Rankin S, Reszka AP, Huppert J, et al. Putative DNA quadruplex formation within the human c-kit oncogene. J Am Chem Soc. 2005;127: 10584-10589.

110. Huppert JL, Balasubramanian S. G-quadruplexes in promoters throughout the human genome. Nucleic Acids Res. 2007;35:406-413.

111. Kato T, Kurahashi H, Emanuel BS. Chromosomal translocations and palindromic AT-rich repeats. Curr Opin Genet Dev. 2012;22: 221-228.

112. Lu M, Dubé I, Raimondi S, et al. Molecular characterization of the $t$ $(10 ; 14)$ translocation breakpoints in T-cell acute lymphoblastic leukemia: further evidence for illegitimate physiological recombination. Genes Chromosomes Cancer. 1990;2:217-222.

113. Raghavan SC, Kirsch IR, Lieber MR. Analysis of the V(D)J recombination efficiency at lymphoid chromosomal translocation breakpoints. J Biol Chem. 2001;276:29126-29133.

114. Tsai AG, Lu H, Raghavan SC, Muschen M, Hsieh C-L, Lieber MR. Human chromosomal translocations at $\mathrm{CpG}$ sites and a theoretical basis for their lineage and stage specificity. Cell. 2008;135:11301142.

115. Sawai Y, Kodama Y, Shimizu T, et al. Activation-induced cytidine deaminase contributes to pancreatic tumorigenesis by inducing tumor-related gene mutations. Cancer Res. 2015;75:3292-3301.

116. Takaishi S, Wang TC. Providing AID to p53 mutagenesis. Nat Med. 2007;13:404-406.

117. Pasqualucci L, Migliazza A, Fracchiolla N, et al. BCL-6 mutations in normal germinal center $B$ cells: evidence of somatic hypermutation acting outside Ig loci. Proc Natl Acad Sci U S A. 1998;95:1181611821.

118. Ramiro AR, Jankovic M, Eisenreich $T$, et al. AID is required for c$\mathrm{myc} / \mathrm{lgH}$ chromosome translocations in vivo. Cell. 2004;118: 431-438.

119. Herceg Z, Hainaut P. Genetic and epigenetic alterations as biomarkers for cancer detection, diagnosis and prognosis. Mol Oncol. 2007;1:26-41.

\section{SUPPORTING INFORMATION}

Additional supporting information may be found online in the Supporting Information section at the end of this article.

How to cite this article: Roy U, Raghavan SC. Deleterious point mutations in T-cell acute lymphoblastic leukemia: Mechanistic insights into leukemogenesis. Int. J. Cancer. 2021; 1-11. https://doi.org/10.1002/ijc.33527 